\title{
Sürdürülebilir Kampüs İçin Kent Mobilyası Tasarımı: Bir Stüdyo Deneyimi
}

\author{
Özlem Candan Hergü1 $1^{1^{*}}$ \\ ${ }^{1}$ Bilecik Şeyh Edebali Üniversitesi, Güzel Sanatlar ve Tasarım Fakültesi, İç Mimarlık ve Çevre Tasarımı Bölümü, Bilecik/Türkiye (ORCID: 0000-0001-7140-0149), \\ ozlem.hergul@bilecik.edu.tr
}

(İlk Geliş Tarihi Aralık 2020 ve Kabul Tarihi Ocak 2021)

(DOI: 10.31590 /ejosat.841443)

ATIF/REFERENCE: Hergül, Ö. C. (2020). Sürdürülebilir Kampüs İçin Kent Mobilyası Tasarımı: Bir Stüdyo Deneyimi. Avrupa Bilim ve Teknoloji Dergisi, (21), 374-380.

$\ddot{O} \mathbf{z}$

Sürdürülebilirlik kavramı sosyal, ekonomik ve çevresel kapsamda irdelenen önemli bir konudur. Toplumların kaynaklarını gelecek nesillerin ihtiyaçlarını gözeterek kullanması kavramın özünü oluşturur. Sürdürülebilirlik ilk tanımlandığı zamandan bu yana çok farklı uygulamalar ekseninde kendine yer bulmuş ve buna uygun modeller geliştirilmiştir. Sürdürülebilirliğin çevresel uygulamalarından biri de doğal malzemelerle, çevresel koşullara dayanıklı, uzun süre kullanılan, fazla bakım istemeyen ve geri dönüştürülebilir kent mobilyaları üretmektir.

Sürdürülebilir kampüs kavramı ise kendi başına bir organizma gibi çalışan üniversite kampüsleri için değerlendirilmesi gereken önemli uygulamalar bütününü oluşturmaktadır. Aydınlatmadan, sulama sistemlerine kadar farklı öğeleri kapsamaktadır. Çalışma kapsamında Bilecik Şeyh Edebali Üniversitesi, Endüstri Ürünleri Tasarımı 4. Sınıf öğrencileri tarafından Kent Mobilyaları Tasarımı II dersi kapsamında hazırlanan 'sürdürülebilir bir kampüs için mobilya tasarlamak' olgusu üzerine geliştirilen projelerin değerlendirilmesi yapılmıştır. Ayrıca sürdürülebilir kampüs mobilyası ve sürdürülebilirlik kavramının öğrencilere doğru aktarılması üzerine irdelemelerde bulunulmuştur.

Anahtar Kelimeler: sürdürülebilirlik, kent mobilyası, sürdürülebilir tasarım, sürdürülebilir kampüs

\section{Urban Furniture Design For Sustainable Campus: A Studio Experience}

\begin{abstract}
The concept of sustainability is an important issue that is examined in a social, economic and environmental context. The use of resources considering the needs of future generations forms the essence of the concept. Since its first definition, sustainability has found place in axis of many different applications and suitable models have been developed. One of the environmental practices of sustainability is to produce urban furniture with natural materials, resistant to environmental conditions, long lasting, does not require much maintenance and can be recycled.

The concept of sustainable campus, on the other hand, constitutes an important set of applications that should be evaluated for university campuses that function as an organism on their own. It covers different items from lighting to irrigation systems. Within the scope of the study, evaluation of the projects developed on the concept of "designing furniture for a sustainable campus" is made which prepared within the scope of Urban Furniture Design II course by Bilecik Şeyh Edebali University, Industrial Product Design 4th grade students. In addition, discussions were made on the correct transfer of sustainable campus furniture and the concept of sustainability to the students.
\end{abstract}

Keywords: Sustainability, urban furniture, sustainable design, sustainable campus

\footnotetext{
* Sorumlu Yazar: Bilecik Şeyh Edebali Üniversitesi, Güzel Sanatlar ve Tasarım Fakültesi, İç Mimarlık ve Çevre Tasarımı Bölümü, Bilecik/Türkiye (ORCID: 0000-0001-7140-0149), ozlem.hergul@bilecik.edu.tr
} 


\section{Giriş}

Kampüs alanları üniversite öğrencilerinin eğitim hayatlarının büyük kısmının geçtiği tasarım bağlamında belirli gereklilikleri olan yerleşimlerdir. Kampüs alanlarında öğrencinin, eğitimcinin ya da personelin kaliteli zaman geçirmesi adına kampüste bazı düzenlemelerin yapılması ve dış mekan kullanımlarının teşvik edilmesi hem öğrenme hem de verimli çalışma açısından önemlidir.

Bir üniversite kampüsü, kentsel sistemin küçük ölçekli bir türüdür. Yol, ulaşım, elektrik gibi bir kentin altyapı unsurlarına sahiptir. Binaları içerir ve enerji kullanan ve atık ürünleri deşarj eden sistemlere sahiptir. $\mathrm{Bu}$ nedenle, bir üniversite kampüsü, geleceğin kentlerinde uygulanabilecek yeşil sistemlerin ve yeşil özelliklerin etkinliğini analiz etmek için bir test ortamı görevi görebilir (Choi et. al 2017). Pek çok üniversite iklim değişikliği sorunları konusunda daha bilinçlidir ve sera gazı emisyonunu en aza indirmek ve iklim değişikliği etkileriyle mücadele etmek için birlikte çalışmaktadır (Anis ve diğerleri 2018). Çünkü, enerji sarfiyatına neden olan üniversite kampüslerini yeşil kampüslere dönüştürmek, karbondioksit emisyonları ve küresel 1sınma gibi acil sorunların üstesinden gelmek ve insanların sağlığını ve refahını artırmak hayati bir önem taşımaktadır (Choi et. al 2017). Üniversite kampüslerinin açık ve yeşil alanları, insanlara sosyal ve kültürel aktivitelerden keyif alma firsatı sunarak, insanların sosyalleşmesine katkı sunmakta ve eğitim kalitesini artırmaktadır (Tel 2020). Üniversite kampüsleri, işleyişleri açısından sürekli bir devinim ve sirkülasyon içerisindedirler. Bu bağlamda hem temel eğitimin bir parçası olarak, hem de çevresel duyarlılığın yayılması açısından toplumsal bazda hassasiyet gerektiren kurumlardır.

\subsection{Sürdürülebilirlik}

Sürdürülebilirliğin temel amacı, kaynak tüketimini azaltmak ve kaynak teminini daha iyi bir seviyeye getirmektir (Amr et al. 2016). Bu kavram, doğal kaynakların akılcı, verimli, tasarruflu ve gelecekte de değerlendirilecek şekilde kaliteli bir niteliğe sahip olmasını, bu süreçte üretimin devam etmesini ve yok olmamasını ifade etmektedir. Kısaca sürdürülebilirlik; değişikliğe ihtiyaç duymaksızın bir durumun devam ettirilebilmesidir (Aras 2019). Son yıllarda, sürdürülebilirlik; dayanıklılık ve dönüşüm, kentleşme ve çevresel değişimin ortaya çıkardığ bir dizi zorluğu yanıtlamayı amaçlayan temel bir kavram haline gelmiştir (Hugo et al. 2018). Sürdürülebilirlik için yaygın olarak kullanılan alternatif terimler arasında koruma, devamlılık, kurumsallaştırma, rutinleştirme ve dayanıklılık bulunur (Moore et al. 2017). Sürdürülebilirliğe yönelik antroposentrik bir yaklaşım sergilenmesi, mevcut ve gelecek nesil insanların refahına değer verir ve sürdürülebilirliğin ortak tanımlarında kendini gösterir (Brown et al. 2019).

\section{Yöntem}

Makalede, öğrencilerin sürdürülebilir kampüs mobilyası tasarım konusunda geliştirdikleri fikirler ve bu fikirler doğrultusunda ortaya çıkan projeler irdelenmiş ve genel bir değerlendirme yapılmıştır. Bu kapsamda çalışma yöntemi içinde öncelikle aşağıda ders akış çizelgesi oluşturulmuştur.

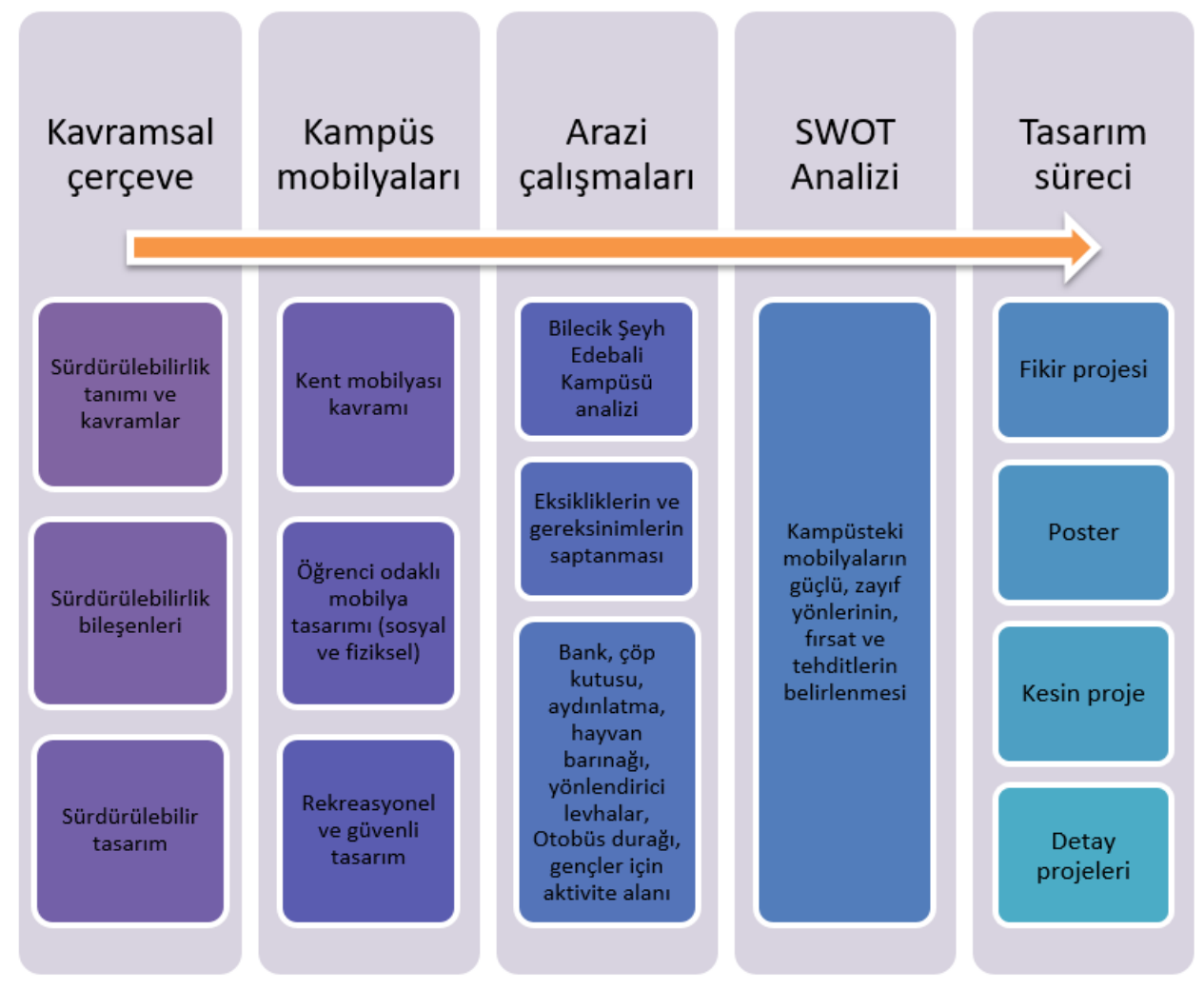

Şekil 1. Kent Mobilyaları Tasarımı II dersi akış diyagramı 
Çalışma yöntemi olarak öncelikle öğrencilere sürdürülebilirlik olgusu çerçevesinde, kavramsal içeriğe yönelik bilgilendirmeler yapılmıştır. Bu doğrultuda geri beslemeli bir süreç üzerinden ilerlenmiş ve sürdürülebilirlik kavramının tanımları, sürdürülebilirlik uygulamaları ve sürdürülebilir tasarımın gereklilikleri üzerinde durulmuştur. Ayrıca, kent mobilyası kavramı, gereklilikleri ve tipleri teorik ders kapsamında, ders programı dahilinde her hafta örneklerle çeşitlendirilerek öğrenciye aktarılmıştır.

İkinci aşamada kampüs mobilyaları örnekleri üzerinde durulmuştur. Öğrenci odaklı tasarım kavramı doğrultusunda beyin firtınası yapılmış ve öncelikle öğrencilerin kampüs gereksinimleri üzerinde durulmuştur. Öğrencilerin sosyalleşmesini besleyecek çoklu kullanıma yönelik mobilyalar, ders çalışma ve yemek yemeye olanak tanıyan öğeler ve güvenlik kavramları üzerine fikirler geliştirilerek, aynı donanımın kampüsten faydalanan öğretim elemanları ve idari personel tarafindan da kullanılabilirliği ön planda tutulmuştur. Bilecik Şeyh Edebali Üniversitesi kampüsünde barınan hayvanlar için de ayrıca tasarım gerçekleştirilmesi düşünülmüştür.

Bir sonraki aşamada kampüs alanında fiziksel analiz çalışmaları gerçekleştirilmiştir. Kampüsteki donatı öğeleri gruplanarak, geliştirilmesi ya da değiştirilmesi gerekenler belirlenmiştir. Bu kapsamda aşağıdaki öğeler çalışmak üzere seçilmiştir.

- Bank

- Çöp kutusu

- Aydinlatma elemanları

- Hayvan barınakları

- Otobüs durakları

- Gençler için aktivite alanları

Daha sonra sınıf içerisinde bu öğelere yönelik bir SWOT analizi yapılmış ve üzerinde durulması gereken veriler ve işlevleri belirlenmiştir.

Bir sonraki aşamada öğrenciler çalışmak istedikleri mobilya tipini seçerek, sürdürülebilir kent mobilyası üretmeye yönelik olarak önce konuya 1 şı tutan bir poster ve fikir projesi geliştirmişler, kritiklerle desteklenen sürecin sonunda ise kesin proje, detay projeleri ve maket aşamalarını kurgulamışlardır. $\mathrm{Bu}$ doğrultuda 6 adet farklı proje ortaya konmuştur. Çalışma kapsamında öğrencilerin ortaya koydukları projeler ve sürdürülebilirlik kavramına yaklaşımları üzerinden değerlendirmelerde bulunulmaktadır. Öğrencilerin bireysel olarak çalıştıkları projeler aşağıda detaylandırılarak; projelerin konsept ve tasarımı, sürdürülebilirlik yaklaşımı, projelendirme aşamaları ve fikir özgünlüğü değerlendirilmektedir. $\mathrm{Bu}$ bağlamda; + (yetersiz), ++ (orta), +++ (iyi) olarak saptanmış olup açıklamalarla desteklenmektedir.

\section{Bulgular ve Değerlendirme}

\subsection{Aqua çeşme projesi ve detayları}

Aqua ismi verilen çeşme projesi kapsamında, kampüsün farklı yerlerinde konumlandırılmış olan içme suyu donanımı; öğrencilerin, personelin ve kampüs hayvanlarının faydalanması üzerine tasarlanmıştır. Üst kısmındaki fotoselli musluk, kişilerin kendi şişe veya mataralarıyla su doldurmalarına ya da doğrudan çeşmeden faydalanmalarına olanak tanımaktadır. Alt kısmında bulunan hazne ise kampüs hayvanlarının su içebilmesi için tasarlanmıştır. Türk ve Osmanlı tarihinde sokak çeşmeleri önemli mimari öğeler olarak yer almaktadır. Projeyle; öncelikle çeşme kültürünün modern bir çizgide sürdürülmesi, özellikle öğrencilerin kendi şişelerine su doldurmaları ve pet şişe tüketiminin azaltılması ve fotoselli bir uygulamayla gereksiz su tüketiminin engellenmesi hedeflenmektedir. Ayrıca fotosel sistemi sebebiyle çeşmeye doğrudan temas gerekmemesi de günümüz sağlık koşulları dikkate alındığında önemli bir çözümdür.

- Aqua projesi, konsept ve tasarım açısından orta seviyede değerlendirilmiştir. Bilecik gibi özellikle Osmanlı tarihi etkisinde bir coğrafya için modern ve geleneksel mimarinin harmanlanarak yansitılması detayında kurgulansa daha etkili ve özgünlük açısından marka değeri daha yüksek bir ürün ortaya çıkabilirdi.

- Sürdürülebilirlik yaklaşımı açısından; bir pet şişenin doğada çözünmesinin yaklaşık 400 yıl aldığı bilgisi doğrultusunda, pet şişe kullanılmasının önemli ölçüde azaltılmasını teşvik eden bir çeşmenin sürdürülebilir çevreye katkısı büyük olacaktır.

- Çalışma sokak ve kampüste barınan hayvanlara su sağlaması açısından da değerlidir.

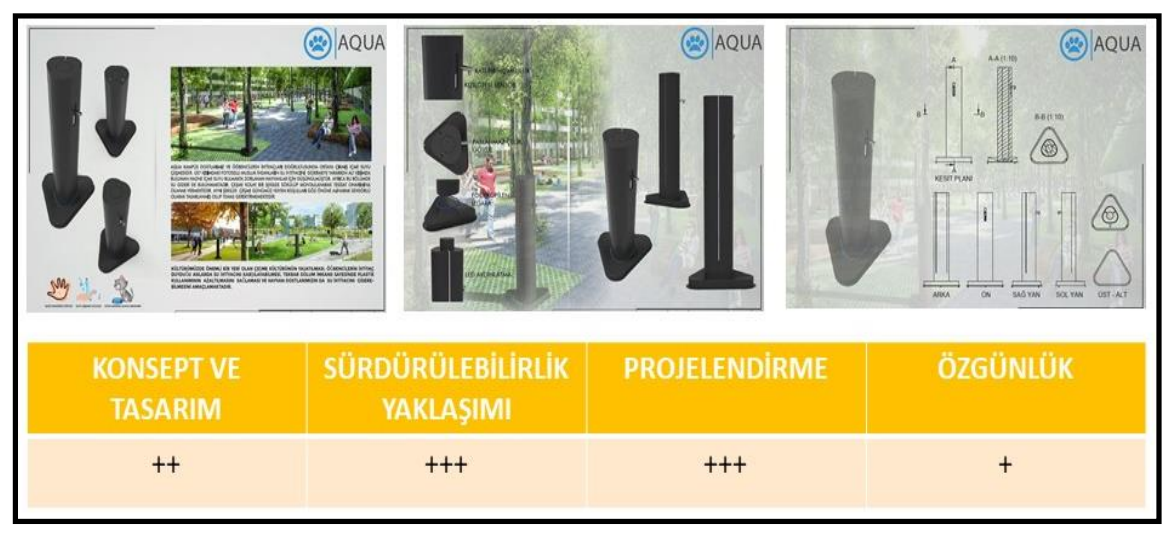

Şekil 2. Aqua projesi ve detayları

\subsection{Block's oturma birimi projesi ve detayları}

Block's ismi verilen oturma birimi projesi kapsamında; öğrencilerin bireysel olarak ve birlikte vakit geçirebilecekleri, yüz yüze iletişime olanak tanıyan, çoklu kullanılabilen, oturma, yaslanma, ayak uzatabilme fonksiyonları sunan, banktan ziyade bir rekreatif donatı sistemi tasarlanmıştır. Üretiminde beton 
kalıplar ve ahşap malzemenin birleştirilerek kullanılması öngörülmüştür.

- Block's projesi, konsept ve tasarım açısından yenilikçi, özgün bir tasarım olup öğrencilerin klasik oturma elemanları yerine farklı sistemlere yönelimini öngörerek tasarlanması bağlamında nitelikli bir projedir.
- Kullanılan malzemeler kalıp beton ve ahșap malzemedir. Ahşap doğal bir malzeme olması sebebiyle çevre dostudur. Beton üretimi ve taşınması esnasında bir miktar enerji harcanan bir malzeme olmakla birlikte ürün; boya, detaylı montaj vb. istemediği için tercih edilebilir. Ayrıca beton ve ahşap geri dönüştürülebilir malzemeler olduğu için de ürün sürdürülebilirlik yaklaşımı açısından olumlu bulunmuştur.

- Projelendirme detaylı olarak hazırlanmıştır ve ürüne ilişkin detay ve ölçülendirme projeleri de sunulmuştur.

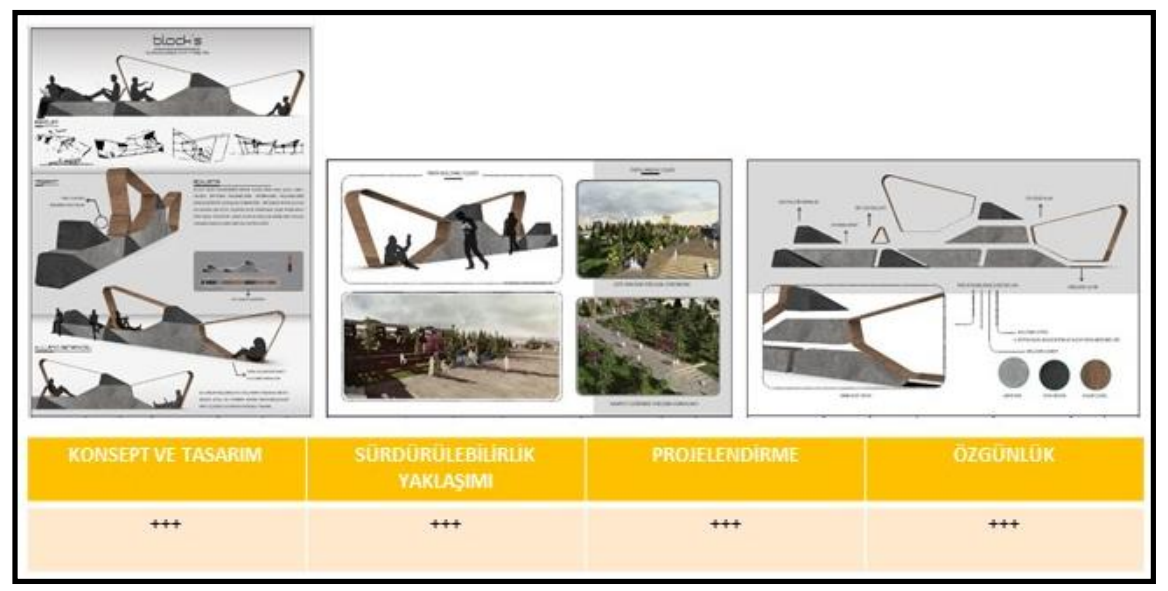

Şekil 3. Oturma birimi projesi ve detayları

\subsection{Curve bank projesi ve detayları}

Çalışma çoklu kullanılmaya uygun ve doğayla uyumlu tasarlanmış bir üründür. Doğal formlar ve kıvrımlı bir sistem öngörülmektedir. Oturma birimleri aralarında da çiçek parterleri tasarlanmıştır.

- Çalışma konsept ve tasarım açısından yeterli görülmemiştir. İnsan ergonomisi açısından sırt desteği olmayan bir mobilyayı uzun süre kullanmak söz konusu değildir. Bu nedenle ürün kullanışlı görülmemektedir.
- Sürdürülebilirlik yaklaşımı açısından doğal malzeme olan ahşap tercih edilmektedir ve metal ayakların kullanımı öngörülmektedir. $\mathrm{Bu}$ nedenle orta seviyede bir yaklaşım sergilediği söylenebilir.

- Projelendirme konusunda ürünün detay ve ölçülendirme kısımlarının yeterli seviyede kurgulanmadığı görülmektedir.

- Özgünlük açısından da tasarımda farklılık yaratan bir ürün olduğu düşünülmemektedir.

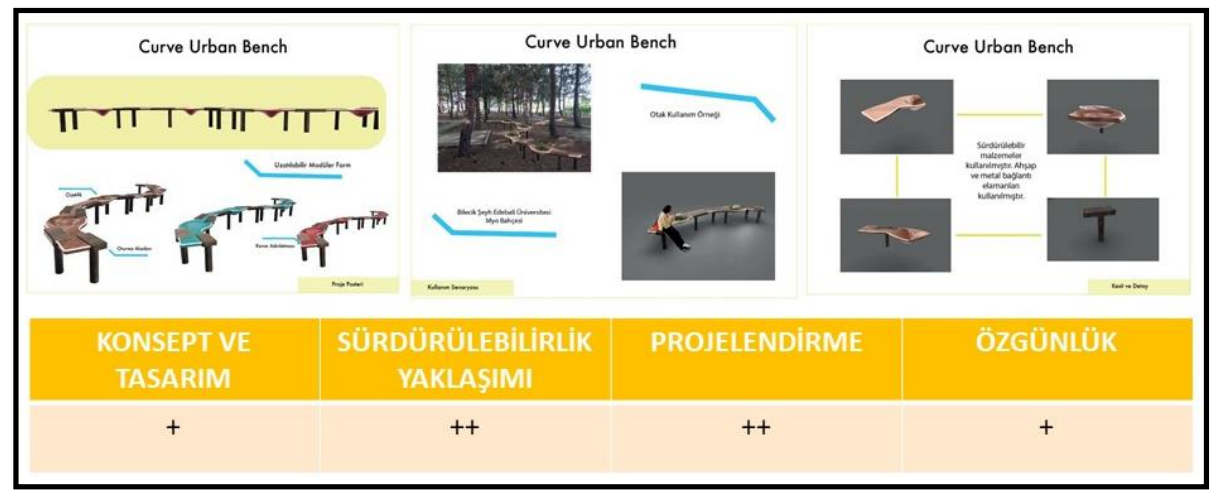

Şekil 4. Oturma birimi projesi ve detayları

\subsection{Akıllı durak projesi ve detayları}

Kampüs içinde düşünülen akıllı durak için öncelikle kampüs mimarisinde de sıklıkla kullanılan Selçuklu yıldızı bütünsel tasarım açısından kullanılmıştır. Durakta güneş paneli, oturma alanları, solar enerjiden beslenen prizler, kampüs haritası ve bilgilendirme ekranları tasarlanmıştır. Durak için kent iklimine uygun, ekolojik toleransı yüksek bitkiler tercih edilmiştir.

- Çalışma konsept ve tasarım açısından, orta dereceli bir çizgi yakalamaktadır. Akıllı durak konsepti dünya genelinde çok çeşitli, özgün örnekleri ve tasarımları içeren kullanımlardır. $\mathrm{Bu}$ nedenle tasarımsal bazda ortalama 
olarak değerlendirilebilecek çalışma, kampüsle uyum açısından yeterlidir.

- Sürdürülebilirlik yaklaşımı açısından; özellikle güneş enerjisini depolama ve dönüştürme olanağı sunduğu ve yerel bitki kullanımı önerdiği için projeyi yeterli olarak nitelendirmek mümkündür.

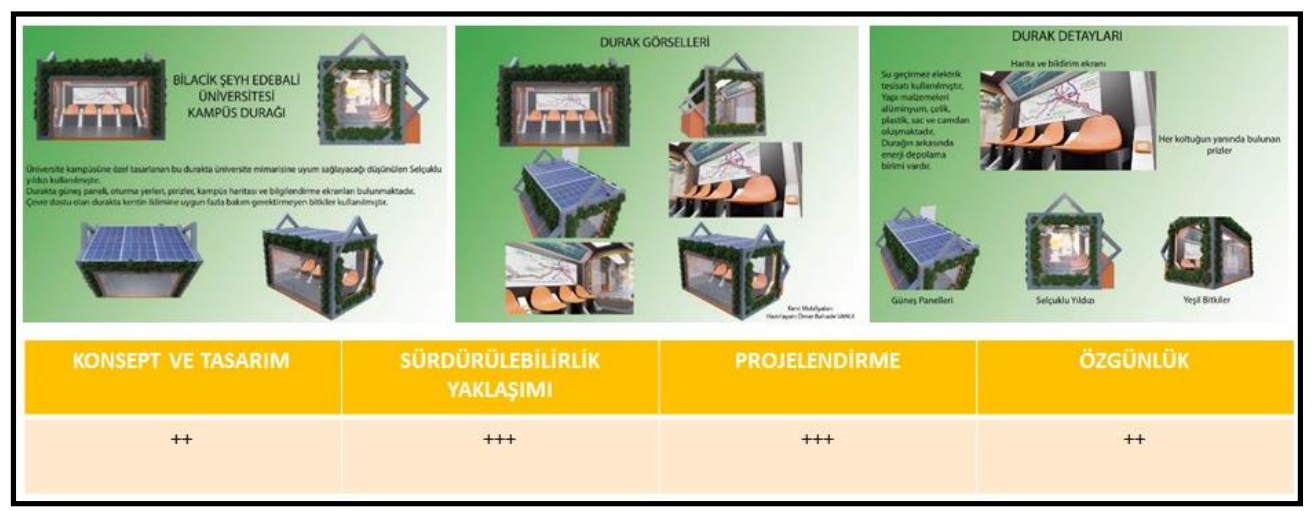

Şekil 5. Akıllı durak projesi ve detayları

\subsection{Kampüs köpekleri için kulübe projesi ve detayları}

Kampüste barınan köpekler için tasarlanan proje, kampüs yaşantısına en uygun kulübenin tasarlanması hedefiyle geliştirilmiştir. Kulübenin alt zemini 1sı yalıtımlı olup, kulübenin üstü oyun alanı ve arkası mama ve su kaplarının da bulunduğu bir mini veranda olarak tasarlanmıştır. Dış koşullara dayanıklı ahşap malzeme tercih edilmiştir.

- Proje konsept ve tasarım açısından detaylı olarak çalışılmış bir projedir. Farklı, yeni hayvan yaşam alanları incelenerek ve kampüs hayvanlarının konforu düşünülerek geliş̧tirilmiştir.

- Sürdürülebilirlik yaklaşımı açısından orta dereceli olduğunu söylemek mümkündür. Doğal bir malzeme olan ahşabın kullanımı dışında sürdürülebilirliği ön plana çıkaran bir yaklaşım sergilenmemektedir.

- Projelendirme detaylı olarak kurgulanmış, ölçülendirme ve detay projeler de sunulmuştur.

- Çalışma yeni dönem köpek kulübelerini izleyen bir çizgidir belirli bir özgünlük seviyesini yakalamaktadır.

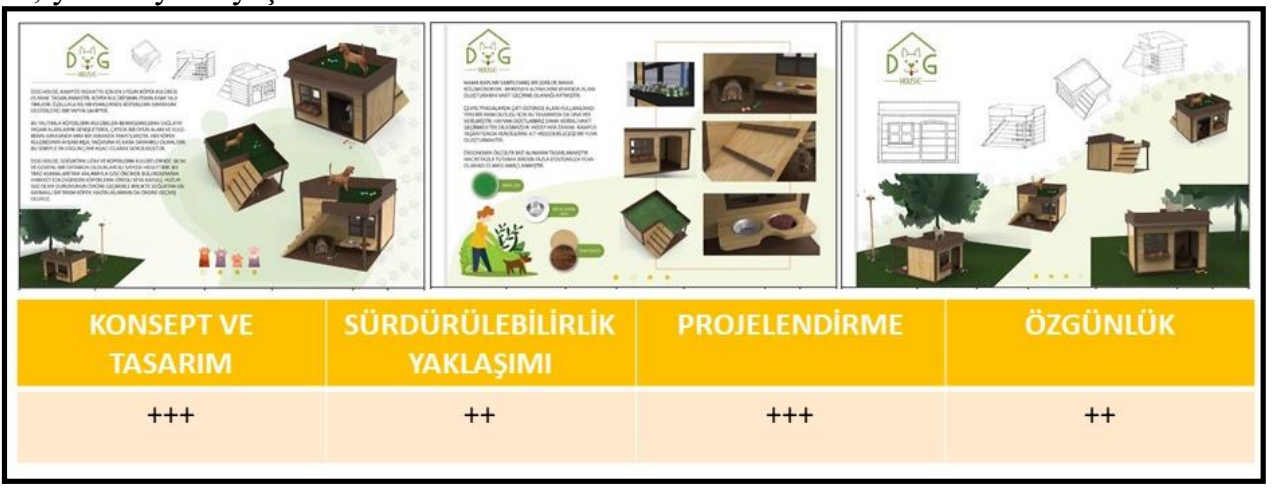

Şekil 6. Köpek kulübesi projesi ve detayları

\subsection{Fiziksel etkinlik alanı projesi ve detayları}

Proje kapsamında öğrenciler için sıralı olarak fiziksel etkinlikler yapabilecekleri bir alan tasarlanmıştır. Tasarlanan ekipmanlar belirli bir dizilim içerisinde düzenlenerek, seri ve ardışık bir şekilde fiziksel etkinliğe olanak tanımaktadır.
- Proje konsept ve tasarım olarak standart diş mekan spor aletlerin konseptinden farklılık göstermektedir. Bu bağlamda tasarım ve özgünlük açısından değerli bir çalışmadır.

- Çalışmada sürdürülebilirlik yaklaşımı ön planda tutulmadığından bu konuda başarılı bulunmamıştır.

- Projelendirme konusunda ana paftaları ve detaylarıyla çalışılmış bir proje olduğundan yeterli bulunmuştur. 


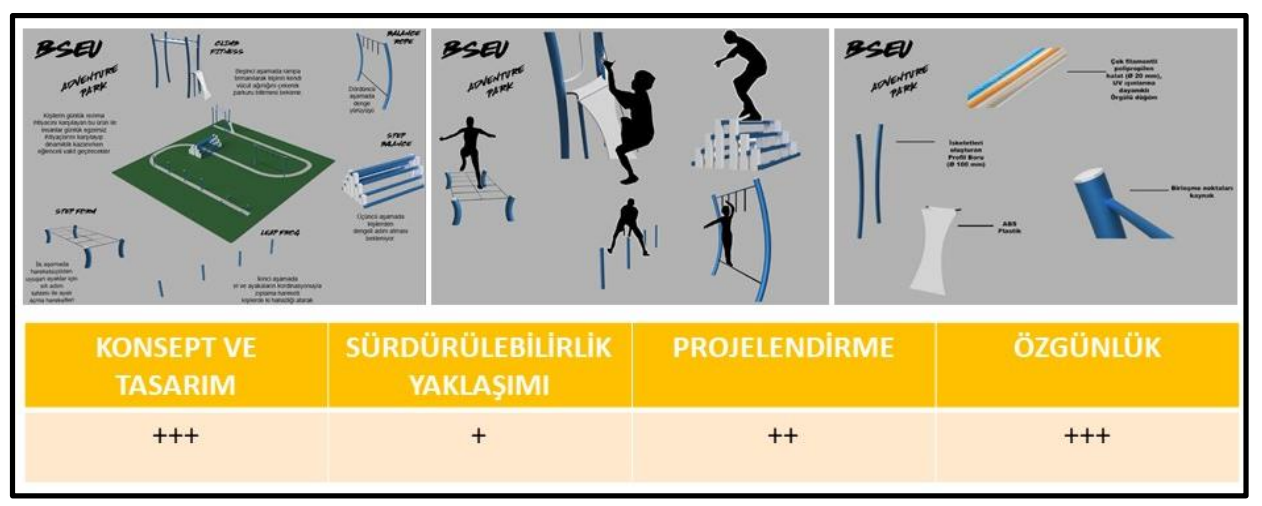

Şekil 7. Öğrenci fiziksel etkinlik alanı projesi ve detayları

\section{Sonuç}

Kent Mobilyası Tasarımı II ders dönemi içerisinde öğrencilere kent mobilyası kavramı, hangi mimari ürünlerin kent mobilyası olarak değerlendirileceği ve kent mobilyası gereklilikleri üzerine bilgilendirme yapılmıştır. Bununla birlikte sürdürülebilirlik kavramı, bileşenleri, alt tanımları ve tasarımda sürdürülebilirliğin sağlanması üzerinde durulmuştur. Öğrencilerin sürdürülebilirlik olgusunu içselleştirerek projelerine yansıtmaları hedefiyle çalışılmıştır.

Malzemenin sürdürülebilir olması, üretim sırasında enerji sarfiyatının az olması, mobilyanın üretim, kullanım ve geri dönüşüm döngüsü sırasında tüm aşamalarda sürdürülebilirliğin ön planda tutulması vurgulanmıştır. Öğrenci çalışmalarının karşılaş̧ırmalı değerlendirilmesi Çizelge 2'de yapılmıştır. Bu bağlamda özellikle sürdürülebilirlik yaklaşımı konusunda 6 projeden 3'ünün daha nitelikli olduğunu söylemek mümkündür. Dolayısıyla çalışmaların \%50'sinin sürdürülebilirlik yaklaşımı sergilediği, \% 50'sinin ise bağlamdan uzak kaldığı saptaması yapılabilir.

Tablo 1. Öğrenci projelerinin karşılaştırmalı değerlendirmesi

\begin{tabular}{|c|c|c|c|c|}
\hline & $\begin{array}{l}\text { Konsept ve } \\
\text { Tasarım }\end{array}$ & $\begin{array}{c}\text { Sürdürülebilirlik } \\
\text { Yaklaşımı }\end{array}$ & Projelendirme & Özgünlük \\
\hline Aqua çeşme & Orta & İyi & İyi & Zayıf \\
\hline $\begin{array}{c}\text { Block's oturma } \\
\text { birimi }\end{array}$ & İyi & İyi & İyi & İyi \\
\hline Curve bank & Zayıf & Orta & Orta & Zayif \\
\hline Akıllı durak & Orta & İyi & İyi & Orta \\
\hline Köpek kulübesi & İyi & Orta & İyi & Orta \\
\hline Etkinlik alanı & İyi & Zayif & Orta & İyi \\
\hline
\end{tabular}

Burada 'Neden öğrencilerin yarısı sürdürülebilirlik konusunu tam olarak projelerine yansitamadı?' sorusu üzerinde durmakta fayda vardır. $\mathrm{Bu}$ sorunun cevabinı ortaya koyacak ve sürdürülebilir tasarım üzerine geliştirilebilecek projeksiyona ilişkin çıkarımlar yapmak üzere geliştirilen öneriler şu şekildedir:

$\checkmark$ Sürdürülebilirlik; temel bir tanım üzerinden çok farklı içeriklerde kendine yer bulmaktadır. Bunlardan biri de sürdürülebilir tasarım kavramıdır. Tasarımda sürdürülebilirlik konusu sadece bir stüdyo dersinin bir bölümünde değil, başlı başına bir stüdyo deneyimi olarak kurgulanmalıdır.

$\checkmark$ Öğrencilerin kavramsal birikimini geliştirmek ve kent mobilyası tasarımı dersini ekolojik çerçevede öğrencilere aktarmak için öncelikle çevresel duyarlılık bilincinin öğrencide gelişmesine yönelik adımlar atılmalıdır.

$\checkmark \quad$ Öğrencinin ekolojik bilincini geliştirmeye yönelik ders içinde dikkatini toplayacak belgesel, fotoğraf vb. görsel öğeler zenginleştirilmeli ve öğrenciye ders dışı okuma listesi verilmelidir.

$\checkmark$ Kent mobilyaları içinden kampüsler için yapılacak tasarımlarda öğrenciyi merkeze alacak şekilde konsept ve ürün geliştirme yapılmalıdır.

Sürdürülebilirlik olgusunun temelinde, çevresel duyarlılık ve kaynak koruma bilinci bulunmaktadır. Bu bağlamda eğitimciye düşen; öğrencinin geri dönüşüm, enerji ve suyu etkin kullanma, tüketim bilinci geliştirme gibi konularda donanım kazanmasını etkin bir şekilde sağlamaktır. 


\section{Kaynakça}

Amr, A.I., Kamel, S., El Gohary, G., Hamhaber, J. (2016). “Water as an Ecological Factor for a Sustainable Campus Landscape”, Procedia - Social and Behavioral Sciences 216 (2016), 181-193.

Anis, M., Afiff, A.Z., Kiswanto, G., Suwartha, N., Sari, R.F. (2018). "Managing university landscape and infrastructure towards green and sustainable campus", E3S Web of Conferences 48, 02001 (2018).

Aras, B.B. (2019). "Kentsel Sürdürülebilirlik Kapsamında Yeşil Çatı Uygulamaları”, Manas Sosyal Araştırmalar Dergisi, 8(1), 469-504.

Brown, K., Adger, N. et. al. (2019). "Empathy, place and identity interactions for sustainability", Global Environmental Change, 56(2019), 11-17.
Choi, YJ., Oh, M., Kang, J., Lutzenhiser, L. (2017). “Plans and Living Practices for the Green Campus of Portland State University”, MDPI, Sustainability, 9(252), 1-16.

Hugo, H., Espinoza, F., Morales, I., Ortiz, E., Perez, S., Salcedo, G. (2018). "Delta Project: Towards a Sustainable Campus", MDPI, Sustainability, 10(3695), 1-27.

Moore, J., Mascarenhas, A., Bain, J., Stratus, S. (2017). "Developing a comprehensive definition of sustainability", Implementation Science (2017), 12 (110), 1-8.

Öztürk Tel, H. (2020). "Design of Unique Urban Furniture in Outdoor Campus Areas", Online Journal of Art and Design, 8(4), 68-83. 